Historic, Archive Document

Do not assume content reflects current scientific knowledge, policies, or practices. 



\section{GLADIOLUS SEED}

The greatest fun we find in the Glad business is in raising new varieties from seeds. This is the way all varieties are originated. Glad bulbs planted beside each other remain true; to get new varieties seeds are planted. It depends on the kinds of seeds planted as to what one gets. The best crosses produce a few good new kinds; poor crosses or seeds from poor varieties are likely to give only disappointment. We have two lots of seeds.

LOT ONF-Hand polenized from the best varieties we have. It is from this lot that we raise our own seedlings. Orer 100 seeds are in this package and the price is $\$ 1$.

LOT TWO-These seeds are selected from the best plants available, but are self polenized or cross polenized by insects. Per package of 100 seeds, 50 cents.

\section{DELPHINIUM SEEDS}

We have seeds selected from several hundred plants, the best varieties saved from thousands of plants. Some few are in dark colors, but the majority are light blue or medium. Singles, doubles and triple petaled florets. Magnificent flowers are certain to develop from these seeds. Delphiniums are very hardy and will grow in any part of the United States. In most places they bloom both in the spring and the fall. They give a gorgeous display of blues and iridescent colorings. Seeds per packet, \$1.

\section{DODROPIN GLAD GARDENS}

Rt. 2, Lewiston Orchards, Lewiston, Idaho 
CIrE is $\mathrm{L}$ $\because$ JAN $221920 \star$ t 